\title{
Deteksi Kantuk Menggunakan Jaringan Saraf Tiruan Radial Basis Function dan Particle Swarm Optimization dengan RR Interval Elektrokardiogram
}

\author{
Ariefah Shalihah, Nuryani Nuryani*, dan Artono Dwijo Sutomo \\ Jurusan Fisika, Fakultas MIPA, Universitas Sebelas Maret, Surakarta \\ *nuryani@mipa.uns.ac.id
}

\begin{abstract}
The drowsiness detection system is designed using Electrocardiogram (ECG) with Radial Basis Function Neural Network and Particle Swarm Optimization (PSO-RBFNN). The Karolinska Sleepiness Scale (KSS) is a reference for drowsiness levels which simplified into alert and drowsy classes. This system uses Pan-Tomkins algorithm to determine the RR interval of ECG. Fifteen statistical features are employed. Training and testing of data using PSO-RBFNN based on cross-validation methods. PSO is used to optimize the main parameters of RBFNN: weights, centers and width. This drowsiness detection system has been tested using the DROZY Database. The result shows that the accuracy of which uses 40 -second segmentation, the hidden neuron number of 150 and 15 statistical features is $88.36 \%$.
\end{abstract}

Keywords : Drowsiness, KSS, ECG, RBFNN, PSO

\section{ABSTRAK}

Sistem deteksi kantuk dirancang menggunakan Elektrokardiogram (EKG) dengan Jaringan Saraf Tiruan Radial Basis Function dan Particle Swarm Optimization (JST RBF-PSO). Karolinska Sleepiness Scale (KSS) menjadi acuan tingkat kantuk yang dikelompokkan menjadi kelas terjaga dan kelas mengantuk. Sistem ini menggunakan algoritma Pan-Tomkins untuk menentukan interval RR dari EKG. Fitur yang digunakan adalah 15 parameter fitur statistik. Pelatihan dan pengujian data menggunakan JST RBF-PSO dengan metode validasi silang. PSO digunakan untuk mengoptimasi parameter utama JST RBF yaitu bobot, pusat dan lebar. Sistem deteksi kantuk ini diuji menggunakan DROZY Database. Hasil penelitian menunjukkan akurasi sistem ini pada segmentasi 40 detik, jumlah neuron 150 dan 15 fitur statistik sebesar $88,36 \%$.

Kata kunci: Kantuk, KSS, EKG, JST RBF, PSO

\section{PENDAHULUAN}

Salah satu penyebab terjadinya kecelakaan lalu lintas akibat dari pengemudi yang mengantuk. WHO melaporkan setiap tahunnya 1,25 juta jiwa meninggal karena kecelakaan lalu lintas ${ }^{[1]}$. Data kecelakaan lalu lintas di Indonesia pada bulan oktober 2017 hingga maret 2019 jumlah korban kecelakaan mencapai 160.457 jiwa diantaranya 23,4\% meninggal dunia ${ }^{[2]}$. Oleh sebab itu, diperlukan penelitian dalam mendeteksi kantuk untuk menurunkan angka kecelakaan lalu lintas.

Kantuk merupakan keadaan peralihan dari terjaga dan tertidur ${ }^{[3]}$. Gejala kantuk dapat diukur secara subjektif dengan Karolinska Sleepiness Scale (KSS). KSS merupakan skala penilaian subjektif kantuk yang sensitif dan telah divalidasi terhadap berbagai ukuran fisiologis ${ }^{[4]}$. Salah satu metode deteksi tingkat kantuk yaitu menggunakan sinyal 
Elektrokardiogram (EKG). Sinyal EKG mendiskripsikan perubahan aktivitas kelistrikan jantung terhadap waktu. Interval RR EKG diukur antara jarak puncak R sebelum sampai puncak R sesudahnya ${ }^{[5]}$. Sinyal EKG menghasilkan fungsi non linear sehingga diperlukan metode pemrosesan sinyal menggunakan ekstraksi fitur.

Beberapa metode klasifikasi sinyal EKG telah diterapkan pada penelitan-penelitian deteksi kantuk seperti Jaringan Saraf Convolutional ${ }^{[6]}$, Analisis Diskriminan Linear ${ }^{[7]}$ dan Jaringan Saraf Tiruan Radial Basis Function ${ }^{[8]}$ dengan mengidentifikasikan EKG menjadi 2 kelas yaitu kelas terjaga dan kantuk. JST RBF memiliki kinerja akurasi yang tinggi dalam mengklasifikasikan data ${ }^{[9]}$, sistem deteksi kantuk menggunakan JST RBF dengan $k$-means clustering mampu menghasilkan akurasi sebesar $81,96 \%{ }^{[8]}$. Oleh karena itu, pada artikel ini dipaparkan sistem deteksi kantuk yang dibangun menggunakan Jaringan Saraf Tiruan Radial Basis Function (JST RBF) dengan optimasi menggunakan Particle Swarm Optimization (PSO) yang memanfaatkan ekstraksi fitur serta Interval RR.

\section{METODE}

Perancangan sistem deteksi kantuk menggunakan metode JST RBF-PSO ditunjukkan pada Gambar 1. Data yang digunakan berupa rekaman EKG dari ULg Multimodality Drowsiness Database atau DROZY Database dengan perekaman selama 10 menit setiap pasien, dan frequency sampling sebesar $512 \mathrm{~Hz}^{[10]}$. Data kemudian diolah menggunakan algoritma Pan-Tomkins untuk memfiltrasi dan mendeteksi puncak R EKG. Hasil penentuan puncak $\mathrm{R}$ digunakan untuk menghitung interval RR. Interval RR berupa nilai aras waktu sehingga diperlukan ekstraksi fitur statistik. Penggunaan fitur statistik bertujuan untuk membedakan nilai variasi fitur antara rekaman EKG kelas terjaga dan mengantuk. Setiap rekaman EKG diberi perlakuan variasi segmentasi waktu 20 detik, 30 detik, dan 40 detik. Hasil segmentasi yang telah diekstraksi fitur dikelompokkan menjadi segmen kelas terjaga dan segmen mengantuk menggunakan JST RBF-PSO berdasarkan metode 5-bagian validasi silang.

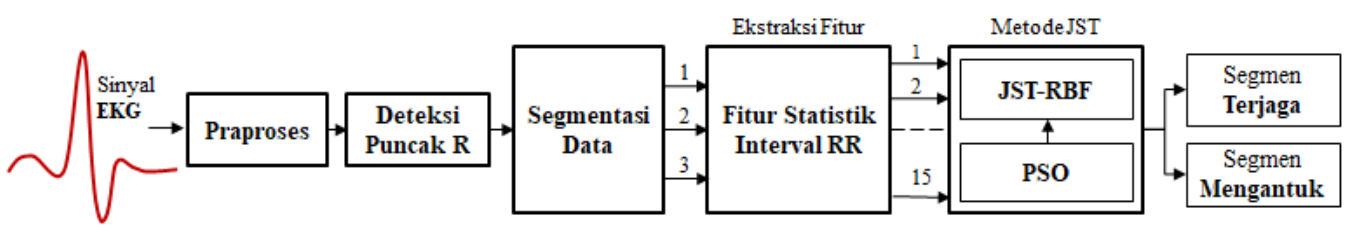

Gambar 1. Rancangan sistem deteksi kantuk

Hasil ekstraksi fitur menjadi masukan pada sistem JST RBF-PSO. JST RBF adalah jaringan hibrid nonlinear yang mengandung lapisan masukan, lapisan tersembunyi dan lapisan output. Pada lapisan tersembunyi dihitung fungsi aktivasinya $f_{a c t}\left(r_{h}\right)$ berdasarkan lebar $\sigma_{h}$ dan jarak euclidean $r_{h}$ dengan persamaan sebagai berikut ${ }^{[11]}$ :

$$
f_{\text {act }}\left(r_{h}\right)=e^{\left(\frac{-r_{h}^{2}}{2 \sigma_{h}^{2}}\right)}
$$

Kemudian, pada lapisan keluaran JST RBF bergantung jumlah total neuron $k$, bobot antara keluaran dan lapisan tersembunyi $\omega_{j i}$, pusat setiap neuron $c_{i}$ dan lebar neuron $\sigma_{i}$, dihitung dengan persamaan sebagai berikut ${ }^{[11]}$ :

$$
c_{j}(x)=\sum_{i=1}^{k} \omega_{j i} \exp \left(\frac{\left\|x-c_{i}\right\|^{2}}{2 \sigma_{i}^{2}}\right)
$$


Algoritma PSO digunakan untuk mengoptimasi parameter RBF (pusat, lebar dan bobot), agar diperoleh kinerja yang optimal. Setiap partikel iterasi memperbaharui kecepatan $v_{i}$ dan posisi partikel $x_{i}$ sebagai berikut ${ }^{[11]}$ :

$$
\begin{aligned}
& v_{i}(t+1)=\omega v_{i}(t)+c_{1} r_{1}\left(p_{i}(t)-x_{p i}(t)\right)+c_{2} r_{2}\left(p_{g}(t)-x_{i}(t)\right) \\
& x_{i}(t+1)=x_{i}(t)+v_{i}(t+1)
\end{aligned}
$$

dimana, $c_{1}$ dan $c_{2}$ adalah koefisien percepatan yang mengendalikan perbedaan setiap particel iterasi. Vektor $p_{i}$ adalah posisi terbaik sebelumnya atau posisi yang memberikan nilai fitness terbaik dari partikel $i$ disebut juga personal best position ( $p$ Best). Vektor $p_{g}$ adalah posisi terbaik diantara $p$ Best dari partikel dalam populasi, atau disebut sebagai global best positions (gBest). Parameter $r_{1}$ dan $r_{2}$ adalah dua angka acak yang didistribusikan secara seragam dalam rentang $(0,1)$. Secara umum, nilai $v$ dibatasi dalam interval $\left[-V_{\max }, V_{\max }\right]$. Dan $\omega$ adalah bobot inersia untuk mempercepat kecepatan konvergensi ${ }^{[12]}$.

Kinerja JST RBF PSO dapat dihitung menggunakan persamaan sebagai berikut ${ }^{[13]}$ :

$$
\text { Akurasi }=\frac{T P+T N}{T P+T N+F P+F N} \times 100 \%
$$

dimana, TP (True Positive) menunjukkan banyaknya segmen mengantuk yang mampu dideteksi dengan benar, FP (False Positive) menunjukkan banyaknya segmen mengantuk yang tidak dapat dideteksi dengan benar, $F N$ (False Negative) menunjukkan banyaknya segmen terjaga yang tidak dapat dideteksi dengan benar, TN (True Negative) menunjukkan banyaknya segmen terjaga yang mampu dideteksi dengan benar ${ }^{[8]}$.

\section{HASIL DAN PEMBAHASAN}

Pada penelitian ini, JST RBF-PSO mendasari pengelompokan segmen interval RR kelas terjaga dan kelas mengantuk. Setiap data segmen dihitung menggunakan 15 parameter fitur staitstik dan telah diberikan target kelas terjaga atau kelas mengantuk. Kemudian seluruh data diolah dengan teknik 5 bagian validasi silang yang membagi data pelatihan dan data pengujian pada JST RBF-PSO. Untuk mengetahui kinerja sistem JST RBF-PSO dilakukan perhitungan akurasi yaitu kemampuan sistem dalam mendeteksi kantuk dan terjaga dengan benar.

Variasi fitur tunggal dilakukan untuk mengetahui fitur terbaik yang mampu menghasilkan akurasi sistem JST RBF-PSO paling optimal. Hasil akurasi JST RBF-PSO fitur tunggal ditunjukkan pada Tabel 1. Akurasi terbaik pada fitur rata-rata geometrik RR ( $f 04)$ dengan nilai akurasi 75,66\%. Fitur rata-rata geometrik RR mampu membedakan RR kelas terjaga dan mengantuk paling baik dibandingkan fitur lainnya. Adapun akurasi terendah pada jangkauan interquartil RR ( $f 06$ ) dengan nilai akurasi 65,41\%. Dalam hal ini acuan untuk melakukan variasi kombinasi fitur menggunakan parameter akurasi diurutkan dari nilai tertinggi hingga terendah.

Variasi kombinasi fitur diharapkan mampu meningkatan akurasi sistem ketika dilakukan penambahan fitur dalam mengelompokkan data agar sesuai target kelas terjaga ataupun mengantuk. Tabel 2. merupakan urutan variasi kombinasi fitur yang digunakan pada sistem JST RBF-PSO. Variasi kombinasi fitur bertujuan untuk menentukan kombinasi yang mampu memberikan hasil akurasi paling optimal pada sistem JST RBF-PSO dalam mengelompokkan data masukan sesuai target kelas. 
Tabel 1. Kinerja JST RBF PSO Variasi Fitur Tunggal

\begin{tabular}{lc}
\hline \multicolumn{1}{c}{ Fitur } & Akurasi $(\%)$ \\
\hline Rata-rata Geometrik RR $(f 4)$ & 75,66 \\
RMS RR $(f 13)$ & 75,32 \\
Rata-rata Harmonik RR $(f 5)$ & 73,82 \\
Rata-rata RR $(f 1)$ & 73,79 \\
Maksimal RR $(f 11)$ & 72,11 \\
Trimmean RR $(f 15)$ & 71,79 \\
Varian RR $(f 2)$ & 71,34 \\
Standar Deviasi RR $(f 3)$ & 71,32 \\
Median RR $(f 9)$ & 71,09 \\
Skewnes RR $(f 8)$ & 69,8 \\
Minimal RR $(f 12)$ & 68,18 \\
Modus RR $(f 10)$ & 67,73 \\
Jangkauan RR $(f 14)$ & 67,55 \\
Kurtosis RR $(f 7)$ & 66,8 \\
Jangkauan Interquartil RR $(f 6)$ & 65,41 \\
\hline
\end{tabular}

Tabel 2. Urutan Kombinasi Fitur JST RBF PSO

\begin{tabular}{ll}
\hline $\begin{array}{c}\text { Fitur } \\
\text { Kombinasi }\end{array}$ & \multicolumn{1}{c}{ Urutan Variasi Kombinasi Fitur } \\
\hline$c f 01$ & $f 4$ \\
$c f 02$ & $f 4 f 13$ \\
$c f 03$ & $f 4 f 13 f 5$ \\
$c f 04$ & $f 4 f 13 f 5 f 1$ \\
$c f 05$ & $f 4 f 13 f 5 f 1 f 11$ \\
$c f 06$ & $f 4 f 13 f 5 f 1 f 11 f 15$ \\
$c f 07$ & $f 4 f 13 f 5 f 1 f 11 f 15 f 2$ \\
$c f 08$ & $f 4 f 13 f 5 f 1 f 11 f 15 f 2 f 3$ \\
$c f 09$ & $f 4 f 13 f 5 f 1 f 11 f 15 f 2 f 3 f 9$ \\
$c f 10$ & $f 4 f 13 f 5 f 1 f 11 f 15 f 2 f 3 f 9 f 8$ \\
$c f 11$ & $f 4 f 13 f 5 f 1 f 11 f 15 f 2 f 3 f 9 f 8 f 12$ \\
$c f 12$ & $f 4 f 13 f 5 f 1 f 11 f 15 f 2 f 3 f 9 f 8 f 12 f 10$ \\
$c f 13$ & $f 4 f 13 f 5 f 1 f 11 f 15 f 2 f 3 f 9 f 8 f 12 f 10 f 14$ \\
$c f 14$ & $f 4 f 13 f 5 f 1 f 11 f 15 f 2 f 3 f 9 f 8 f 12 f 10 f 14 f 7$ \\
$c f 15$ & $f 4 f 13 f 5 f 1 f 11 f 15 f 2 f 3 f 9 f 8 f 12 f 10 f 14 f 7 f 6$ \\
\hline
\end{tabular}


Tabel 3. Kinerja JST RBF PSO pada Kombinasi Fitur dengan Segmentasi 20 detik, 30 detik dan 40 detik

\begin{tabular}{cccc}
\hline \multirow{2}{*}{ Fitur } & \multicolumn{3}{c}{ Akurasi (\%) } \\
\cline { 2 - 4 } & 20 detik & 30 detik & 40 detik \\
\hline$c f 1$ & 72,88 & 75,3 & 72,14 \\
$c f 2$ & 77 & 80,3 & 75,29 \\
$c f 3$ & 77,05 & 79,05 & 76,26 \\
$c f 4$ & 76,86 & 78,04 & 76,31 \\
$c f 5$ & 79,98 & 82,93 & 82,55 \\
$c f 6$ & 79,73 & 83,21 & 82,1 \\
$c f 7$ & 81,64 & 82,46 & 84,74 \\
$c f 8$ & 81,67 & 83,07 & 83,02 \\
$c f 9$ & 82,25 & 82,91 & 83,02 \\
$c f 10$ & 84,56 & 86,77 & 86,69 \\
$c f 11$ & 84,21 & 86,84 & 86,19 \\
$c f 12$ & 82,39 & 85,77 & 86,88 \\
$c f 13$ & 83,94 & 86,41 & 87,02 \\
$c f 14$ & 84,18 & 86,66 & 86,48 \\
$c f 15$ & 84,14 & 86,29 & 87,67 \\
\hline
\end{tabular}

Pada Tabel 3. merupakan akurasi JST RBF PSO dengan variasi segmentasi 20 detik, 30 detik dan 40 detik menggunakan variasi kombinasi fitur. Hasil tabel tersebut menunjukkan peningkatan akurasi sistem secara signifikan setelah ditambahkan fitur jika dibandingkan dengan variasi fitur tunggal. Terdapat selisih akurasi yang cukup besar antara penambahan fitur dibandingkan dengan hanya satu fitur. Misal pada segmentasi 20 detik dengan nilai akurasi $72,88 \%$, sedangkan setelah ditambahkan menjadi dua fitur, akurasi meningkat menjadi $77 \%$. Variasi kombinasi fitur dapat memberikan pengaruh yang tinggi terhadap meningkatnya akurasi sistem JST RBF-PSO. Berdasarkan nilai akurasi kombinasi fitur dengan variasi segmentasi menunjukkan bahwa semakin banyak fitur yang digunakan maka akurasi semakin meningkat, namun penambahan fitur berlebihan dapat menurunkan akurasi sistem. Hasil variasi kombinasi fitur, pada segmentasi 20 detik diperoleh akurasi paling tinggi pada cfl0 sebesar 84,56\%, untuk segmentasi 30 detik diperoleh akurasi tertinggi pada cfl1 sebesar 86,84\%. Sedangkan segmentasi 40 detik diperoleh akurasi tertinggi dibandingkan dengan segmentasi lainnya pada kombinasi seluruh fitur cfl5 mencapai $87,67 \%$. 
Tabel 4. Kinerja JST RBF PSO pada Segmentasi 20 detik, 30 detik, dan 40 detik dengan Variasi Jumlah Neuron

\begin{tabular}{cccc}
\hline \multirow{2}{*}{ Neuron } & \multicolumn{3}{c}{ Akurasi (\%) } \\
\cline { 2 - 4 } & 20 detik & 30 detik & 40 detik \\
\hline 70 & 83,1 & 85,55 & 86,9 \\
80 & 83,88 & 85,86 & 87,24 \\
90 & 83,94 & 86,29 & 87,48 \\
100 & 84,02 & 86,38 & 87,76 \\
110 & 83,89 & 87,64 & 86,83 \\
120 & 84,05 & 87,11 & 88,29 \\
130 & 83,81 & 86,07 & 87,05 \\
140 & 83,98 & 86,16 & 86,5 \\
150 & 84,05 & 87,04 & 88,36 \\
160 & 83,77 & 86,2 & 86,45 \\
\hline
\end{tabular}

Peningkatan kembali akurasi pada sistem JST RBF-PSO dengan melakukan variasi jumlah neuron tersembunyi. Untuk variasi neuron, digunakan akurasi fitur kombinasi yang tertinggi. Pada segmentasi 20 detik digunakan cflo, segmentasi 30 detik cfl1 dan segmentasi 40 detik cfl5. Variasi neuron dilakukan setelah variasi kombinasi fitur untuk meningkatkan kembali akurasi sistem JST RBF-PSO yang lebih tinggi. Jumlah neuron pada lapisan tersembunyi mempengaruhi banyaknya fungsi aktivasi dalam pengelompokan data. Tabel 4. menunjukkan bahwa sistem JST RBF-PSO memiliki kinerja paling optimal pada segmentasi 40 detik dan jumlah neuron 150 dengan akurasi sebesar 88,36\%. Berdasarkan variasi segmentasi terhadap variasi jumlah neuron, semakin panjang segmentasi cenderung menghasilkan akurasi lebih tinggi, akan tetapi jumlah neuron yang berlebihan dapat menurunkan akurasi sistem JST RBF-PSO.

\section{KESIMPULAN}

Pada penelitian ini, JST RBF-PSO dapat diaplikasikan pada sistem deteksi kantuk dengan menganalisis interval RR EKG yang terkelompokkan menjadi segmen kelas terjaga dan segmen kelas mengantuk. Interval RR EKG dihitung menggunakan 15 parameter fitur statistik. Variasi fitur tunggal menunjukkan fitur rata-rata geometrik memiliki kinerja terbaik dalam membedakan kantuk dan terjaga dengan akurasi sebesar 75,66\%. Variasi kombinasi dan variasi segmentasi diperoleh kinerja terbaik menggunakan 15 fitur pada segmentasi 40 detik dengan akurasi sebesar 87,67\%. Hasil kinerja terbaik JST RBF-PSO dengan jumlah neuron 150 menghasilkan akurasi sebesar 88,36\%.

\section{DAFTAR PUSTAKA}

1 WHO. 2015. Global Status Report on Road Safety 2015. 15 Oktober 2018. http://www.who.int/violence_injury_prevention/road_safety_status/2015/en/.

2 KORLANTAS POLRI. 2019. Accident Data. 28 Agustus 2019. http://korlantas-irsms.info/graph/accidentData.

3 Zwahlen, D., Jackowski, C., \& Pfaffli, M. 2016. Sleepiness, driving, and motor vehicle accidents: A questionnairebased survey. Journal of Forensic and Legal Medicine, 44,183-187. 
4 Kaida, K., Takahashi, M., Åkerstedt, T., Nakata, A., Otsuka, Y., Haratani, T., \& Fukasawa, K. 2006. Validation of the Karolinska sleepiness scale against performance and EEG variables. Clinical Neurophysiology, 117, 1574-1581.

5 Goldberger, A. L., Goldberger, Z. D., \& Shvilkin, A. 2012. Goldberger's Clinical Electrocardiography: A Simplified Approach. Elsevier Saunders.

6 Lee, H., Lee, J., \& Shin, M. 2019. Using Wearable ECG/PPG Sensors for Driver Drowsiness Based on Distinguishable Pattern of Recurrence Plots. Electronics, 8(2) 192.

7 Vicente, J., Laguna, P., Bartra, A., \& Bailon, R. 2011. Detection of driver"s drowsiness by means of HRV analysis. Computing in Cardiology (CinC), 89-92.

8 Maftukhaturrizqoh, O., Nuryani, N., \& Darmanto, D. 2018. Drowsiness detection using radial basis function network with electrocardiographic RR interval statistical feature. Journal of Physiscs, Conf. Series 1153.

9 Anzihory, E., Nuryani, N., \& Darmanto, D. 2016. Sistem Deteksi Fibrilasi Atrium menggunakan Fitur RR Elektokardiogram dengan Jaringan Syaraf Tiruan. Jurnal Fisika dan Aplikasinya, 12(2), 57-60.

10 Massoz, Q., \& Verly, J. G. 2016. The ULg Multimodality Drowsiness Database (called DROZY) and Examples of Use. IEEE Winter Conference in Applications of Computer Vision (WACV).

11 Korürek, M., \& Doğan, B. 2010. ECG beat classification using particle swarm optimization and radial basis function neural network. Expert Systems with Applications, 37(12), 7563-7569.

12 Shi, Y., \& Eberhart, R. 1998. A Modified Particle Swarm Optimizer. IEEE International Conference on Evolutionary Computation, 69-73.

13 Li, G., \& Chung, W. Y. 2013. Detection of Driver Drowsiness Using Wavelet Analysis of Heart Rate Variability and a Support Vector Machine Classifier. Sensors, 13, 16494-165511. 